\title{
Criterios \\ Pasado, presente y futuro de un archivo fotográfico
}

José Manuel Suárez Garmendia

Profesor Titular del Dpto. de Historia del Arte. Universidad de Sevilla

\section{Resumen}

El artículo presenta la fototeca del Laboratorio de Arte de la Universidad de Sevilla, un fondo de imágenes fotográficas en diferentes soportes. Además de recoger los inicios de este proyecto y su trayectoria durante el pasado siglo, el texto describe el estado actual del fondo y sus posibilidades de crecimiento. En la actualidad, la consulta de la base de datos generada por la fototeca puede ser consultada en la web www.us.es. La aplicación permite diversos tipos de consultas entre la galería de más de 32.000 imágenes digitalizadas.

\section{Palabras clave}

\section{Fotografias}

Fototeca del Laboratorio de Arte (Sevilla)

Fototecas

Historia

Patrimonio documental

Sevilla
La fototeca del Laboratorio de Arte es un fondo documental de imágenes fotográficas en diferentes soportes. En conjunto es una parte importante de un patrimonio visual que nos permite hacer presentes innumerables objetos, muchos de ellos desaparecidos o transformados, así como multitud de situaciones irrepetibles que forman parte de nuestro acervo cultural. Es uno de los componentes fundamentales de un proyecto iniciado a principios del siglo XX por Francisco Murillo Herrera. Su finalidad fue crear un archivo de imágenes que, como complemento a una gran biblioteca de temas artísticos, constituyera la estructura básica de un departamento universitario dedicado al estudio de la historia del arte.

En un principio se desarrolló de forma precaria bajo la dirección y los esfuerzos personales de Murillo para cubrir las necesidades prácticas demandadas por la asignatura de Teoría de la literatura y de las artes de la que él era titular. Con el paso de los años y el trabajo de muchas personas fue evolucionando hacia un archivo documental de absoluta necesidad para el estudio y el conocimiento de nuestra historia contemporánea.

En sus fondos están recogidos gran parte de un patrimonio visual relacionado con la historia, la arqueología, el arte, la etnografía y la propia actividad social de nuestra ciudad, ampliándose paulatinamente al ámbito provincial, nacional y posteriormente a Hispanoamérica. Hoy alberga colecciones de fondos y de vistas editadas por los principales museos europeos y americanos. En este sentido, también destacaríamos que aunque la colección se inicia cuando Murillo Herrera accede a la cátedra en 1906, pronto recibe donaciones de amigos, compañeros y alumnos a los que él contagia el entusiasmo por un proyecto en el que tiene fe. Las procedencias de estas donaciones son muy variadas lo que va a contribuir a ampliar el arco temporal de los fondos penetrando paulatinamente en el siglo XIX de manera que hoy podemos encontrarnos entre sus positivos series y álbumes de fotógrafos de importancia contrastada para la historia del medio.

La necesidad de las imágenes para el estudio práctico de las obras de arte era obvia y se había manifestado con anterioridad. En 1901 el catedrático de la asignatura de Teoría de Literatura y de las Artes, el Doctor Segalá Estadella, había solicitado de la Junta de Facultad un aparato de proyección por ser imposible dar el carácter práctico necesario... así como para los exámenes de la misma ${ }^{1}$. Pero las dificultades para adquirir un aparato de este tipo, que suponemos que podía ser de cuerpos opacos, eran grandes y no creemos que fueran de tipo económico precisamente. De forma provisional se resolvió la situación autorizando al catedrático Doctor Segalá a que pudiera utilizar los libros de la biblioteca para poder examinar de láminas a sus alumnos ${ }^{2}$.

Cuando Murillo Herrera accede en 1907 a la citada cátedra se va a encontrar con las mismas dificultades que la Junta de Facultad pretende paliar de la misma manera, por lo que el mismo catedrá- 
tico vuelve a solicitar un proyector con las diapositivas correspondientes para lo cual argumentaba de forma insistente que la belleza de las artes plásticas solo pueden apreciarse con la contemplación de las mismas y si esto puede alcanzarse con las que hay en esta ciudad es imposible realizarlo al explicar en cátedra los grados si quiera no sea más que los principales de la evolución artística por que ni aquí, con lo monumental que es esta ciudad, ni en parte alguna existen ejemplares de todas ellas... ${ }^{3}$ Esta vez tuvo más éxito en sus peticiones y lo que queda claro es la intención de Murillo de abordar el proyecto de la adquisición de las imágenes fotográficas que le permitieran a través de una gran colección cubrir todas las necesidades derivadas de la enseñanza de la historia del Arte. Su amplitud de miras trasciende los aspectos locales poniendo de relieve que el campo de estudio es mucho más amplio. Desde un principio pretende que estas imágenes fotográficas, ordenadas en un archivo, sirvan para el público en general, para el aficionado al arte, para los estudiantes a distintos niveles, para los investigadores y otros humanistas, incluso para instituciones que proporcionan servicios culturales, editoriales y profesionales del mercado del arte como los galeristas, marchantes, anticuarios etc. Su mentalidad abierta a cualquier tipo de innovación se engrandece con sus frecuentes viajes al extranjero donde analiza las enseñanzas y la investigación de las universidades alemanas adonde viajó con frecuencia y donde se proveía no sólo de ideas sino también de materiales fotográficos de imposible adquisición aquí. Tal es el caso de las colecciones editadas por los grandes archivos comerciales o por los distintos museos europeos así como cámaras fotográficas, placas sensibles, productos químicos, etc. Por otra parte, se dio cuenta del deterioro y pérdida que sufría el patrimonio por la ignorancia generalizada del valor artístico de las muchísimas piezas que se guardaban, por inercia o por su valor sentimental y religioso, en el seno de parroquias, conventos y demás instituciones religiosas y civiles a lo largo de toda la geografía, lo que le impulsó hacia un proyecto cuyos frutos no tardaron en aflorar. Pronto recurrió a la ayuda de sus discípulos para acometer el inicio de un catálogo histórico artístico de la provincia tomando como modelos aquellos que se iban realizando por otros puntos de la geografía española y como primera medida funda lo que entonces se llamó Gabinete Fotográfico Artístico. Éste fue el germen de una actividad que desarrolló a partir de ahora con la intención, además de la función didáctica que ya hemos señalado, de documentar el estado de los bienes culturales del entorno y poder evaluar el tipo y velocidad de deterioro que sufrían.

De alguna manera se trataba de crear su propio museo imaginario adelantándose a las propuestas que años más tarde hará André Malreaux para el conocimiento de las obras de arte valiéndose de la imagen fotográfica. No obstante, pensamos que la intención de Murillo Herrera estaba más cerca del modelo de archivo de las casas comerciales que funcionaban por Europa como Fratello Alinari, George Braum, o por España, como la de J. Laurent y sus descendientes, Roig y Lacoste o incluso en Sevilla la saga de los Beauchy,
Garzón, Almela, Linares, etc. A todos ellos les compró imágenes de sus catálogos pero estos no podían cubrir las necesidades demandadas por un especialista, un investigador o los nuevos descubrimientos que iban surgiendo. A estos archivos comerciales, por otra parte, no se podía acudir en busca de otros detalles, de los diferentes puntos de vista de las obras tridimensionales, de lo que no estuviera en los canales de los anticuarios o museos, de las colecciones particulares y de todo aquello que se encontraba en lugares por descubrir. Por ello se vio en la necesidad de hacer él su propia colección aprovechando su afición hacia el medio fotográfico así como sus conocimientos químicos, pues era farmacéutico. Además tenía el convencimiento de que la imagen fotográfica era el sistema referencial más idóneo para el conocimiento y el estudio de la obra de arte.

Otra vía que aprovechó para el engrandecimiento de la colección fue la de las donaciones. Su prestigio y su labor docente al frente del Laboratorio de Arte movieron a muchos sevillanos a ceder sus propios fondos adquiridos cuando la imagen, y sobre todo la fotográfica, eran objeto de colección y de prestigio. Por este proceder ingresaron muchas fotografias antiguas que hoy se atesoran en el fondo de positivos. En 1905 realiza un Ilamamiento, a través del periódico El Liberal, proclamando en una encuesta que estaba en disposición de aceptar como donativo cualquier tipo de fotografía para enriquecer su proyecto. Muchos amigos y compañeros acudieron a esta llamada que incrementó los fondos con colecciones verdaderamente importantes tanto por su número como por su aspecto documental. Esta fue una actitud muy acertada pues en este momento acudieron no pocos sevillanos a la llamada de Murillo, como fueron sus alumnos, colaboradores y otros muchos. Con esta actuación quedó abierto un camino por el que posteriormente accederán fondos más importantes cuantitativamente que aquí no podemos citar en su totalidad pero de los que destacamos la colección de don Carlos de Borbón y su esposa doña María Luisa de Orleáns con algunas imágenes pertenecientes a los Duques de Montpensier y a la Familia Real. Está constituida por un conjunto de varios cientos de imágenes de muy diversa procedencia que actualmente están en proceso de digitalización. Otras, también destacables, serían los negativos y positivos de los viajes por Oriente de don Francisco de las Barras de Aragón, catedrático de ciencias, los de José Sebastián y Bandarián, canónigo de la catedral, los de los hermanos Antonio y José Maria Nandín, Diego Angulo, Alejandro Guichot, Antonio Sancho Corbacho, José Hernández Díaz y un largo etcétera que poco a poco irán surgiendo conforme se vayan digitalizando todos los fondos de la fototeca.

Con el paso de los años, el prestigio del Laboratorio de Arte, institución universitaria fundada por Murillo y que aglutinaba a profesores e investigadores en el proyecto común del estudio de la obra de arte, se fue consolidando apoyándose en el quehacer científico desarrollado por sus componentes y allegados que formaban la comunidad universitaria. Esta labor se ve materializada en numerosos trabajos editoriales que se realizan con presupuestos económicos del propio laboratorio de cuyos fondos fotográficos se nutrían o 


\section{Criterios \\ Pasado, presente y futuro de un archivo fotográfico \\ José Manuel Suárez \\ Garmendia}

se hacían ex profeso y luego pasaban a engrosar la fototeca como donación de los propios autores. Muchas son las publicaciones de trabajos de investigación que se han servido de las fotografías aquí atesoradas como principales referentes. De entre ellas destacariamos por ser muy gráficas y por su carácter local La escultura andaluza, dirigida por Diego Angulo y publicada en 1927, Edificios religiosos destruidos por los marxistas en los pueblos de la provincia de Sevilla, de Hernández Díaz y Sancho Corbacho, publicado en 1937, Los planos de los monumentos arquitectónicos de América y Filipinas, de Diego Angulo, publicado en 1939, los trabajos sobre Bordados y bordadores sevillanos (siglos XVI al XVIII) de Isabel Turmo, publicado en 1945, los cuatro tomos del inacabado Catálogo arqueológico y artístico de la provincia de Sevilla de Hernández Díaz, Sancho Corbacho y Francisco Collantes de Terán, que salieron entre los años 1939-1954 y fue el proyecto editorial que más negativos aportó al archivo. En los años de 1927 también se recogieron muchos de los negativos realizados sobre la restauración de las vidrieras de la Catedral, que aprovechó Nieto Alcaide para publicar su tesis doctoral sobre este tema. Otros trabajos de Sancho Corbacho como La cerámica andaluza, La arquitectura barroca o la Iconografía de Sevilla se realizaron con imágenes de la fototeca, pero también incorporaron a este fondo otras muchas realizadas por el propio autor. Asi mismo muchas publicaciones se han servido de este archivo y autores tan prolíficos como Hernández Díaz, de la Banda y Vargas, Bernales Ballesteros, Serrera Contreras, al igual que otros que estamos próximos al entorno del Laboratorio de Arte nos hemos servido de su grandeza acudiendo en busca de ese testimonio que probaba la existencia o el estado de tal pintura o cual arquitectura.

La continuidad de la actividad del fondo fotográfico queda garantizada cuando cesa Murillo por jubilación en 1945, con los siguientes directores del laboratorio que se mostraron siempre solícitos a las actividades del archivo y siguieron en la labor de engrandecimiento fomentando donaciones o promocionando trabajos de documentación. En este sentido destaca la aportación de Enrique Marco D'Orta sobre temas americanos y varios álbumes de Canarias o las donaciones realizadas por Hernández Díaz de multitud de imágenes que, reunidas en álbumes, no se habian publicado en el Catálogo Arqueológico y Artístico de la provincia de Sevilla. A este último había que añadir los reportajes encargados en los momentos finales de su actividad como director del Laboratorio de Arte, en torno a los cambios que se producían en el caserío de la ciudad en la década de los 60 .

Desde el punto de vista técnico hay que resaltar la existencia de dos fondos en función del soporte y el material empleado aunque ambos son fotográficos. Por un lado tenemos los negativos o imágenes matrices soportadas en vidrio o en diferentes tipos de acetatos cuyos tonos están invertidos y son producidos por sistemas de revelado químico. Su número asciende a unos 35.000 y abarcan todos los formatos homologados que van desde el paso universal al gigantesco de
$30 \times 40$ centímetros siendo el más numeroso el de $13 \times 18$. Este fondo de negativos ha sido escaneado en los últimos años y publicado en el portal de la Universidad de Sevilla como www.fototeca.us.es.

Por otro lado, está el fondo de positivos, imágenes soportadas en papel o cartulina. No todas son de tipo fotográfico, ya que hay también impresos a tinta por los más diversos sistemas siendo frecuentes las fototipias como el caso de las tarjetas postales, xiliografías, litografías y algún otro tipo de impreso. Los positivos fotográficos, por regla general, son gelatinobromuros y algunas celoidinas utilizadas en los positivos del siglo XIX. Sus tamaños son variadísimos, no se atienen a ningún patrón y su número, aún no calculado, puede pasar de los 50.000. Su procedencia también es muy diversa, muchos son vintages de los negativos del propio archivo, otros de las diferentes donaciones que hemos recibido y otros de colecciones comerciales de los principales editores de fotografía europeos y españoles. Actualmente se está trabajando en el escaneado y documentación de estos positivos cuyo resultado se alojará en la base de datos de la citada web de forma que podremos consultar de manera global todos estos campos.

\section{Situación actual}

Las últimas imágenes que entran en el archivo lo hacen en 1973 cuando, por falta de presupuesto y a partir de este momento, el archivo se sume en la más completa inactividad, sólo alterada por algunos profesores que, aún con ciertas limitaciones, consultan y utilizan los negativos originales para sacar copias fuera de la universidad al no haber personal dedicado a esta tarea. Esta inactividad provoca también el desconocimiento de los fondos lo que a su vez produce un deterioro por falta de atención que es irreversible. A las imágenes en negativo se llegaba a través de una ficha catalográfica con un número de registro que remitía a una caja de un tamaño determinado, y dentro de ésta a un orden. El sistema era bueno pero al no haber ningún responsable, y dada la complejidad del mismo, produjo numerosos desplazamientos y equívocos que era tanto como la pérdida de ese documento, siendo irrecuperable. Por otra parte, el examen de las imágenes se realizaba en el propio documento puesto al trasluz después de sacarlo del sobre contenedor. Ni que decir tiene que todas estas operaciones exponían a los negativos a los usos más arriesgados para su conservación.

Con lo positivos la situación no era mejor pues estaban depositados en cajas inapropiadas en una sala pública con el agravante de que éstos no tenian orden ni ficha referencial.

Cuando en 1985 recibi el encargo de ordenar los fondos comenzamos por recuperar el material y restituirlo a su lugar para lo que hubo que desmontar y contrastar las 3.500 cajas contenedoras del total de negativos y comprobar con las fichas de registro cada una de éstas. Ya en este paso pudimos contrastar el grado de deterioro de estos 
negativos así como faltas y roturas. Sobre todo, era importante el grado de metalización y sulfuración que afectaba a todos los negativos en razón directa a sus años de existencia. Éste es un proceso de deterioro lógico en este material, generalmente producido por unas condiciones medioambientales agresivas pero especialmente porque no se han podido o no se han llegado a neutralizar los elementos sensibles, en este caso las sales de plata, al 100\% debido a lavados o fijados incompletos. Sin lugar a dudas éste es el proceso degenerativo más común que afecta tanto a positivos como a negativos y que de una forma u otra, en función del tratamiento, acabará por debilitar la imagen hasta hacerla desaparecer. Otro deterioro más grave que el anterior, ya que las imágenes son irrecuperables al menos por ahora, es el que nos encontramos en unas series que se realizaron entre los años 1956 al 1958 por el fotógrafo Antonio Palau y que afecta aproximadamente a unos 300 negativos. Consiste básicamente en la separación de la emulsión del soporte de forma que la imagen queda afectada de un craquelado irregular que hace inviable su positivado. Detectamos un fuerte olor a ácido acético en los contenedores afectados y comprobamos que los soportes eran de acetato o triacetato y nunca de vidrio, mucho más estable dimensionalmente. El proceso degenerativo se iniciaba por los bordes del negativo, presentando un aspecto rizado, extendiéndose luego hacia el centro y formando ampollas de aire que le dan un aspecto general de craquelado lo que inutilizaba la imagen. Este fenómeno descrito por Fuentes de Cía se produce por bruscos cambios térmicos que posiblemente no ocurrieran en el laboratorio pues otros negativos del mismo tipo, y que estaban con los afectados, no lo sufrieron. Independientemente de estas causas intrínsecas en la degradación y destrucción de las imágenes fotográficas, nos teníamos que enfrentar a la labor de poner en uso y hacer consultable el fondo de una manera racional. No podía ser que para preservar de la destrucción a esos documentos los pusiéramos a buen recaudo en unas condiciones ambientales ideales. Como todos los documentos, existen para ser vistos y estudiados, por lo tanto había que conjugar ambas cuestiones, las inherentes a la conservación y las inherente a la difusión, contradictorias las dos desde el punto de vista operativo. Efectivamente, como ya habiamos constatado, de las múltiples causas de deterioro descritas en los manuales ninguna ejercía una acción tan nefasta para estos negativos como la manipulación por el hombre para el examen de los mismos. Se habla de la acción destructora de los microorganismos y agentes químicos ambientales, pero muy poco de la acción destructora de los "macroorganismos" cuyos efectos pocas veces son recuperables.

Ante esta situación, el único camino viable para garantizar el uso de los documentos sin exponerlos era la duplicación, lo que planteaba varias opciones. Tradicionalmente en los fondos de esta clase se venía utilizando para la copia el soporte fotográfico. De esta forma nos desviamos muy poco del original con el que, salvo el tamaño, presenta gran similitud, consiguiendo un duplicado de segunda generación de gran utilidad para la consulta. El sistema más apropiado era el famoso microfilm sobre película de $35 \mathrm{~mm}$, muy versátil y con una variedad en el mercado de películas capaz de enfrentarse a cualquier situación además de permitirnos utilizar equipos normalizados que podriamos incluso manipular por nuestros propios medios. En principio esta duplicación alcanzaría sólo a los materiales más degradables como los negativos pero, poco a poco, se haría extensivo a los positivos.

La opción podía haber sido válida para este tipo de documentos pero evidentemente tenía una serie de inconvenientes que hay que evaluar y decidir. Hemos de tener en cuenta que esa copia de seguridad (sólo esto justifica el esfuerzo) es también una duplicación de los problemas (espacio, conservación, cuidados, dinero...). No obstante el mayor de los inconvenientes está en las limitaciones y restricciones que suponen las consultas. Hoy, con ayuda de la digitalización y nuevas tecnologías de telecomunicaciones, estos problemas han pasado a un segundo plano, posibilitándonos dirigir los esfuerzos hacia la protección física de los originales y hacia la documentación de las imágenes. La difusión a través de Internet no tiene comparación con ningún sistema de consulta. El archivo fotográfico del Laboratorio de Arte, a pesar de ser por ahora un archivo de carácter local, ha pasado de ser un auténtico desconocido a poseer una media de 1.250 consultas diarias en este último mes de mayo.

De todos modos, y dejando a un lado el sempiterno problema de los dineros, ya que estamos hablando de un fondo documental histórico y singularísimo, protegido por la Ley del Patrimonio Histórico Español, somos partidarios de que la duplicación debería hacerse en los dos soportes. En digital, por las ventajas de difusión y la aplicación de herramientas y filtros que mejoran la profundidad de la lectura con cualquier programa de edición de imágenes; y en analógico, en tamaños cuya relación sea 1:1 con respecto al original, conseguido por contacto para no perder las sensaciones de las copias en papel. Estas copias de segunda generación, además de seguridad permiten reproducirlas para exposiciones y otros usos.

A la vista de esta situación, en 1998 y con el apoyo material de los Vicerrectorados de Relaciones Institucionales y el de Investigación, iniciamos la digitalización de los negativos con la ayuda de dos becarios. Previamente tuvimos que resolver los problemas de espacio y el cambio de contenedores. Este último asunto es de capital importancia para la conservación del material negativo, que ya tenía daños visibles causados por las gomas de los cierres y por las tintas de las identificaciones de los sobres, asi como otras inherentes e la higroscopicidad de las cajas contenedoras y a las estanterías de madera acribilladas de polillas.

Mejorar esta situación, recuperar material disperso y poner a punto los sistemas de consulta fueron objetivos primordiales. Éramos conscientes de que estábamos rompiendo con una actitud tradicional en el tratamiento del fondo fotográfico. La forma era de lo más novedosa para aquellos momentos pues no teníamos referente aunque nos fuimos dando cuenta que avanzábamos por buen camino. 


\section{Criterios \\ Pasado, presente y futuro de un archivo fotográfico \\ José Manuel Suárez \\ Garmendia}

Con un material que actualmente seria muy escaso (Pentium III a 250 Mhz), utilizando Photoshop 5, fuimos volcando la imagen digital y la información a una base de datos elemental de Access 97 diseñada para nuestras necesidades que entonces se ceñian a unas pocas tablas en función de los datos aportados por las fichas existentes en unos ficheros de hierro organizados en su tiempo de actividad con muy buen criterio. No se pudieron rellenar todos los campos pues se carecía de información y en este sentido se fue respetuoso al máximo sin añadir nada ni siquiera aquellos datos que eran evidentes y reflejando hasta las equivocaciones y notas manuscritas marginales. Dentro del proyecto y en un futuro próximo, partiendo de estos datos, trataremos de ampliar en lo posible esta documentación. A través de las opciones de la aplicación se generaba una imagen en TIFF en 300 ppp siendo tamaño suficiente para un archivo manejable pero con la necesaria información para las exigencias del público al que podian ir dirigidas. Teniendo en cuenta que son imágenes en blanco y negro y que hay una importante diferencia en el tamaño de los formatos, obteníamos unos archivos de 8 a $10 \mathrm{Mb}$ por término medio, más que suficiente para un estudio icónico y, en caso de presentarse alguna excepcionalidad, pues ahi estaban los documentos. A partir de este máster en TIFF, la aplicación guardaba también un JPG con pérdida poco significativa para la pantalla del ordenador y una compresión de 72 puntos por pulgada que se adjuntaba automáticamente a nuestra base de datos. Los TIFF eran vaciados en cds que, poco a poco, se fueron convirtiendo en nuestra Fototeca Virtual.

Posteriormente, y a la vista de los resultados obtenidos en esta primera etapa de trabajo, el servicio correspondiente de la universidad aceptó colocar en el portal de la misma todas las digitalizaciones del fondo de negativos, para lo que pusieron a punto una aplicación "ad hoc" que está teniendo un éxito espectacular.

La aplicación web para la consulta de la base de datos se sirve desde una dirección de la Universidad de Sevilla (www.fototeca.us.es) y en principio se ha planteado compatible con cualquier tipo de cliente web que consulte dicho servicio.

Se ha hecho especial hincapié en que todo el sistema informático que sirve la aplicación funcione en un entorno de software libre con licencia GPL y corriendo bajo el sistema operativo GNU/Linux. De hecho, el software servidor web utilizado es Apache y el código desarrollado incorpora secuencias en lenguaje Java. Toda la información, a excepción de las imágenes, se guarda en una base de datos MySQL. Para facilitar el tratamiento de la información presentada se han utilizado tecnologías XML.

La aplicación permite diversos tipos de consultas, desde las más sencillas, por campos, hasta las más avanzadas, las cuales resuelven un potente motor que permite ir refinando progresivamente una inicial mediante operadores lógicos. Además de estos tipos de consultas, se han definido otras más directas, entre ellas la que permite la localización de registros por fotógrafos o la que selecciona conforme a unas series tipo agrupadas por similitud de temática.

Actualmente la base de datos dispone de una galería de más de 32.000 imágenes digitalizadas como copias máster de alta calidad.

Para el almacenamiento de dichas imágenes originales, en el servidor de la Universidad, se ha elegido el formato TIFF con una variante de compresión sin pérdidas basada en el algoritmo LZW. La resolución de la captación de las imágenes fue de 300 puntos por pulgada, suficiente en principio para la mayoría de las imágenes de gran tamaño. De manera puntual y sólo para los formatos pequeños se utilizó una resolución mayor. Los tamaños de dichas imágenes varian entre los varios megabytes hasta alcanzar los veinte megabytes para una sola.

Con objeto de optimizar la consulta de estas imágenes por Internet a los distintos tipos de perfiles de usuarios, la Fototeca dispone de un sistema de tratamiento de imágenes que adapta éstas a tamaños más razonables para la consulta vía web. En este caso y de manera univoca, existe una miniatura para cada imagen original que es la que sirve en las consultas.

Esta miniatura o versión reducida de la imagen se genera directamente a partir de la original una vez redimensionada su matriz a 72 puntos por pulgada, similar a la resolución de un monitor convencional, y 14 × $14 \mathrm{~cm}$, lo que arroja un total de 800 por 800 puntos. Posteriormente son servidas en formato JPG, compresión con pérdidas no significativas de calidad inherentes a dicho formato. Dicha conversión supone una drástica reducción del tamaño de la imagen redundando por ello en una óptima gestión y eficiencia del servicio.

Finalmente la aplicación incluye una parte de acceso restringido para los editores y catalogadores de los fondos de la misma con objeto de que puedan realizar sus tareas desde Internet, es decir, desde cualquier sitio.

Actualmente se está escaneando el fondo de positivos que irán pasando en tiempo real a la red ya que a partir de ahora somos administradores de la aplicación lo que nos permitirá una mayor fluidez para poner en consulta estos archivos. Como complemento, y para filtrar equívocos y deficiencias, hemos abierto un Foro desde el que estamos en contacto con los usuarios.

\section{Notas}

${ }^{1}$ Archivo Histórico de la Universidad de Sevilla. Libro de Actas de la Facultad de Filosofia y Letras.1901-21. Legajo 1.229. 6 de noviembre de 1901.

\footnotetext{
${ }^{2}$ Ibid. Junta de Facultad de 13 de junio de 1902.
}

${ }^{3}$ Ibid. Junta de Facultad de 10 de diciembre de 1907 